24 U.A.R. J. Amin. Prod. Vol. 11 No. 2, pp. 273-274 (1971).

\title{
NUTRITION AND CHFMICAL STUDIES ON SUGAR-CANE PITH, COTTON SEED HULLS AND DRIED TOMATO PULP.
}

$B y$

A. Agou-Eu-Hassan and E. M. OMar

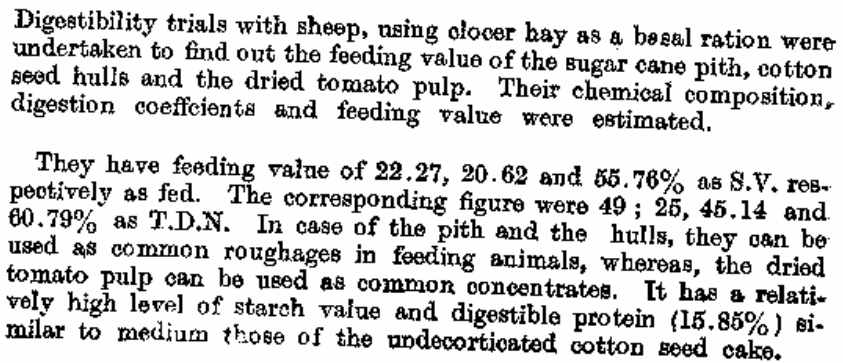




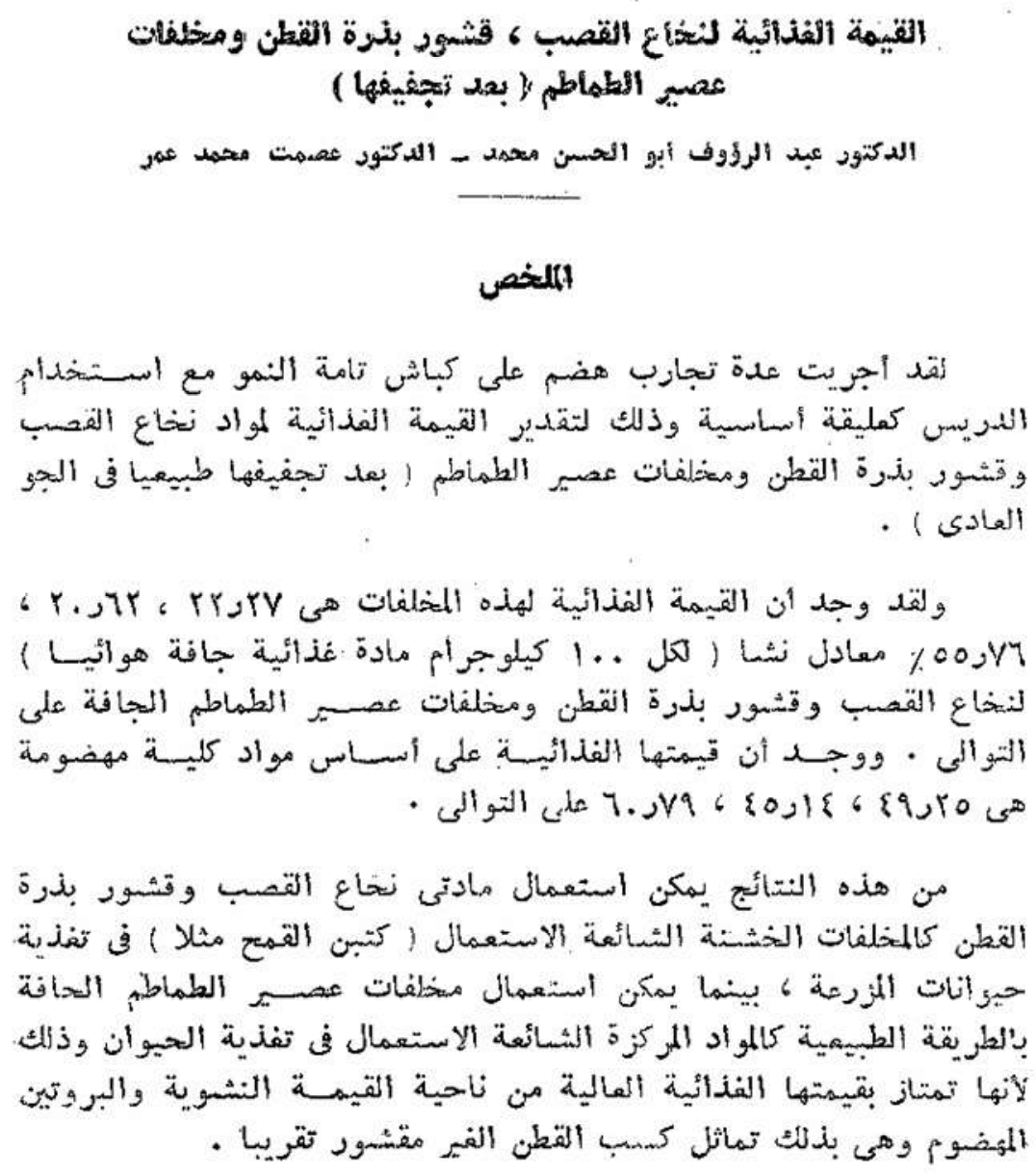

